OLIVEIRA, C.A.S.; MAROUELLI, W.A.; SANTOS, J.R.M.; BOITEUX, L.S. Produção de escleródios de Sclerotinia sclerotiorum e severidade de oídio em cultivares de ervilha sob diferentes lâminas de irrigação. Horticultura Brasileira, Brasília, v. 18, n. 1, p. 16-20, março 1999.

\title{
Produção de escleródios de Sclerotinia sclerotiorum e severidade de oídio em cultivares de ervilha sob diferentes lâminas de água.
}

\author{
Carlos Alberto da S. Oliveira; Waldir Aparecido Marouelli; Jorge Roland M. dos Santos; Leonardo S. \\ Boiteux \\ Embrapa Hortaliças, C. Postal 218, 70.359-970 Brasília - DF.
}

\section{RESUMO}

Foi estudado o efeito de lâminas de água sobre o número de escleródios produzidos por Sclerotinia sclerotiorum, a severidade de oídio causada por Erysiphe pisi e a produção de matéria seca da parte aérea em ervilha (Pisum sativum L.) sob condições de solo e clima do Brasil Central. O delineamento experimental foi de blocos ao acaso, com parcelas subdivididas e quatro repetições. As lâminas de água, aplicadas através de uma única linha de aspersão, variaram entre 125 e 499 mm. As cultivares estudadas foram Maria, Luíza, Marina, Mikado, Triofin, Viçosa, Amélia e Kodama. A matéria seca da parte aérea das plantas não variou entre as cultivares, mas aumentou com a lâmina total de água aplicada. O número de escleródios produzidos nas plantas aumentou significativamente com o aumento da lâmina de água aplicada e não diferiu entre cultivares semiáfilas e cultivares de folhas normais. As cultivares Marina, Mikado e Luíza mostraram uma produção de escleródios significativamente inferior à observada na cultivar Triofin. Lâmina de água e cultivar interagiram significativamente para severidade de oídio avaliada aos 70 dias após o plantio. O aumento da lâmina de água total aplicada na cultura reduziu a severidade de oídio nas cultivares suscetíveis Amélia e Mikado. As cultivares Maria e Marina apresentaram potencial de serem utilizadas em áreas com problemas de Sclerotinia.

Palavras-chave: Pisum sativum L., Erysiphe pisi, manejo da irrigação, doença, controle.

\begin{abstract}
Sclerotia of Sclerotinia sclerotiorum production and powdery mildew severity in pea cultivars under different water depths.

The effect of water depth on the number of sclerotia produced by Sclerotinia sclerotiorum, oidium severity caused by Erysiphe pisi, and top plant dry matter of dry pea (Pisum sativum L.) was studied under soil and climate conditions of Central Brazil. It was used a randomized complete block design with four replications (cultivar as a factor and a split plot on water depth). Water depths, applied through a single irrigation sprinkler line, varied from 125 to 499 $\mathrm{mm}$, and the cultivars studied were Maria, Luiza, Marina, Mikado, Triofin, Viçosa, Amélia and Kodama. Top plant dry matter did not vary among cultivars; however, it increased with total water depth applied. Number of sclerotia produced in infected plants increased significantly as water applied increased and did not differ for semileafless and normal leaf cultivars. Cultivars Marina, Mikado and Luiza showed a significant reduced number of sclerotia in comparison with cv. Triofin. Water depth and cultivar interacted significantly for oidium severity evalueted 70 days after planting. Increasing water depth applied to the crop reduced oidium severity on the susceptible cultivars Amélia and Mikado. Cultivars Maria and Marina showed good potential for use in areas infected with Sclerotinia.
\end{abstract}

Keywords: Pisum sativum L., Erysiphe pisi, irrigation management, disease, control.

(Aceito para publicação em 02 de dezembro de 1999).

$\mathrm{O}$ Brasil, por vários anos, importou praticamente toda a ervilha (Pisum sativum $L$.) necessária para suprir a demanda das indústrias de processamento. Entretanto, entre 1977 e 1987, o país se mostrou com potencial para tornar-se exportador, em razão da rápida expansão da área cultivada no Brasil Central. Esta região é caracterizada por inverno seco, com baixa umidade relativa do ar e temperatura amena. Tais condições são adequadas à produção de sementes de alta qualidade fisiológica (Andreoli, 1979), reduzem o perigo da ocorrência de doenças (Oliveira, 1965) e exigem o cultivo sob irrigação.

A irrigação é uma das práticas que mais favorece o aumento da produtividade da cultura de ervilha (Haddock \& Linton, 1957; Hawthorn \& Polland, 1966,
Marouelli et al., 1991, Chauhan, et al., 1992), tornando-se por isso uma prática indispensável. Em regiões com distribuição irregular de chuvas é possível obter razoáveis produções, sem irrigação desde que as plantas não sejam submetidas a severo déficit hídrico por ocasião do florescimento e do enchimento das vagens (Salter, 1962; Salter, 1963; Salter \& Willians, 1967; Behl et al., 1968), principalmente por ocasião do enchimento das vagens (Miller et al., 1977).

Apesar do sucesso que a cultura da ervilha obteve no Brasil Central, há escassez de informações relacionadas ao desempenho de novas cultivares plantadas no país, diante das múltiplas interações água-solo-planta-doença, principalmente aquelas relacionadas à doenças de solo e de folha.
Entre as principais doenças que atacam a lavoura de ervilha no Brasil Central está a podridão-de-esclerotínia, causada pelo fungo Sclerotinia sclerotiorum, relatada como doença de solo e causadora de grandes danos a diversas lavouras na região de Cerrados (Café Filho, 1985). Os danos podem ser diretos, com morte de plantas e redução da produção, mas o maior problema reside na inviabilização de áreas para novos plantios, pois o fungo permanece no solo por muitos anos, não existindo métodos eficazes para a sua erradicação (Café Filho, 1985; Santos et al., 1993). A alta multiplicação e disseminação deste fungo pode se tornar um dos fatores limitantes à produção de ervilha para grãos nas regiões produtoras do país (Santos \& Reifschneider, 1990), ainda 
mais porque não há cultivares resistentes a este patógeno.

A arquitetura da planta de ervilha e as altas densidades de plantio, aliadas a outros fatores, podem ajudar a criar um microclima mais ou menos favorável à podridão-de-esclerotínia. Em feijão, plantas com arquitetura significativamente mais densa, devido à maior quantidade e proximidade de folhas, mostraram-se com maior incidência da doença (Schwartz \& Gaves, 1980). Tal fato sugere que cultivares áfilas ou semiáfilas de ervilha podem apresentar menores níveis de severidade dessa doença (Santos, 1990).

Outra doença de importância na cultura de ervilha na região do Planalto Central é a doença de folha causada por oídio (Erisiphe pisi), considerada endêmica (Santos et al., 1990) e que apresenta diversas cultivares suscetíveis a essa doença. $\mathrm{O}$ fungo reduz a biomassa vegetal podendo promover perdas acima de $50 \%$ na produção (Café Filho et al., 1988). O efeito favorável da chuva, do orvalho e da irrigação por aspersão no desenvolvimento do oídio foi relatado por Yarwood (1957). Por outro lado, a incidência de oídio decresceu durante o período de chuvas (Schnathorst, 1965), sugerindo um possível efeito de remoção ou lavagem de esporos de oídio pela ação mecânica da água da chuva ou da irrigação sobre as partes infectadas da planta. Trabalhos mais recentes não foram encontrados na literatura tratando sobre a interação entre água e doenças causadas por esclerotinia e oídio, em especial, para condições tropicais.

Este trabalho teve por objetivo avaliar o desempenho da biomassa aérea de oito cultivares de ervilha, incluindo duas semi-áfilas, e quantificar a produção de escleródios de Sclerotinia sclerotiorum e a severidade de oídio nestas cultivares, quando submetidas a diferentes níveis de água no solo.

\section{MATERIAL E MÉTODOS}

O experimento foi realizado no campo experimental da Embrapa Hortaliças, em Brasília (DF), em Latossolo Vermelho-Escuro, fase cerrado e textura argilosa, em uma área infestada naturalmente por S. sclerotiorum e conduzido du- rante a época fria e seca do ano que vai de abril a setembro.

As práticas culturais adotadas foram as recomendadas pela Embrapa Hortaliças (Giordano et al., 1984). Foram estudadas as cultivares de ervilha Maria, Luíza, Marina, Mikado, Triofin, Viçosa, Amélia e Kodama. Todas as cultivares têm características de adaptação a regiões tropicais e apresentam ciclo entre 100 e 120 dias. As cultivares Amélia e Kodama são semi-áfilas; Amélia e Mikado são consideradas suscetíveis ao oídio (Giordano et al., 1988) e as demais resistentes.

O delineamento experimental foi de blocos ao acaso, com parcelas subdivididas e quatro repetições. A área total de cada subparcela foi de $24 \mathrm{~m}^{2}$ sendo a área útil de $8 \mathrm{~m}^{2}(4,0 \times 2,0 \mathrm{~m})$. O espaçamento entre linhas de plantio foi de 17 cm sendo distribuídas cerca de 35 sementes por metro linear.

Ao contrário de Hanks et al. (1980), que considerou cultivar como parcela principal e nível de irrigação como subparcela, os tratamentos deste experimento consistiram da combinação de seis níveis de água correspondendo a 499, 415, 331, 259, 197 e 176 mm (obtidos até 107 dias após o plantio e dos quais 124 mm são provenientes de chuvas), localizados nas parcelas principais, com as oito cultivares localizadas nas subparcelas. Uma única linha de aspersores foi utilizada para todo o experimento, conforme metodologia proposta por Hanks et al. (1980), para obter os seis níveis de água. Os aspersores foram espaçados de $6 \mathrm{~m}$ entre si e proporcionaram um raio molhado médio de $13 \mathrm{~m}$.

A lâmina de água aplicada foi medida por meio de coletores (latas de óleo de um litro) em cada tratamento de irrigação, dispostos em apenas um lado da linha de aspersão. Para possibilitar a germinação adequada em todas as parcelas, até a época de início dos tratamentos, foi aplicada a lâmina de água de $50 \mathrm{~mm}$ pelo sistema de aspersão convencional.

A partir dos resultados de Marouelli et al. (1991), a freqüência de irrigação foi determinada com base na leitura média (quatro repetições) de tensiômetros em cada subparcela do tratamento de irrigação mais próximo da linha de aspersores, considerando-se a tensão de $35 \mathrm{kPa}$, a $15 \mathrm{~cm}$ de profundidade, como limite para reposição de água ao solo durante o ciclo da cultura.

Para fins do manejo da água do solo, a capacidade de retenção de umidade do solo, relacionando os teores volumétricos de água $(\theta)$, em $\%$, com as tensões de água (h), no intervalo entre 10 e $1.500 \mathrm{kPa}$, foi representada pela equação a seguir:

$$
\theta(\mathbf{h})=42,153 \mathbf{h}^{-0,062}\left(\mathbf{r}^{2}=0,92\right)
$$

Para as cultivares estudadas foram avaliados os efeitos de lâminas totais de água sobre: peso seco da parte aérea após a separação dos grãos, grau de severidade de oídio 70 dias após o plantio e número de escleródios de $S$. sclerotiorum existentes junto aos grãos, após a colheita e trilhagem da parte aérea das plantas. Outros dados de produção foram obtidos e estão sendo publicados em um outro trabalho. O grau de severidade de oídio, inoculado naturalmente sob condições de campo, foi quantificado em cada parcela por dois avaliadores, aos 70 dias após o plantio (lâminas de água correspondentes a 303, 250, 204, 162, 125 e $114 \mathrm{~mm}$, das quais $63 \mathrm{~mm}$ proveniente de chuvas), com o uso da seguinte escala de notas adaptada de Bohn \& Whitaker (1964): 1 = ausência de doença (zero plantas infectadas); 2 = incidência baixa (menos de $33 \%$ das plantas); 3 = incidência média (33 a $66 \%$ de plantas) e 4 = incidência alta (mais de $66 \%$ das plantas).

\section{RESULTADOS E DISCUSSÃO}

Não ocorreu interação entre cultivar e lâmina de água para peso seco (biomassa) da parte aérea e número de escleródios presentes nos grãos colhidos, indicando efeitos semelhantes do fator cultivar dentro das lâminas estudadas. Entretanto, houve interação para severidade de oídio indicando que cada genótipo pode responder de forma diferenciada com o aumento da lâmina de água. Como o fator lâmina de água não foi aleatorizado, não foi válido o respectivo teste estatístico " $F$ ", porém, os efeitos de lâmina d'água foram bastante óbvios para severidade de oídio e número de escleródios. $\mathrm{O}$ fator cultivar não foi significativo para o peso seco final da parte aérea realizado após a separa- 


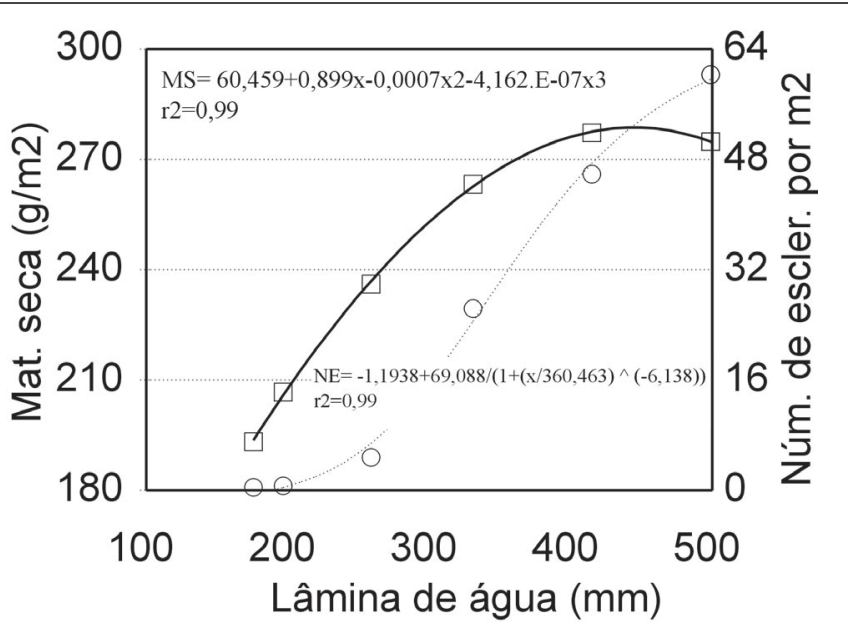

$\square$ Matéria seca o Num. de escleródios

Figura 1. Valores observados e ajustados de produtividade média de matéria seca da parte aérea de plantas $\left(\mathrm{g} / \mathrm{m}^{2}\right)$ e número médio de escleródios por $\mathrm{m}^{2} \mathrm{em}$ função da lâmina total de água aplicada, em mm. Médias obtidas com oito cultivares de ervilha. Brasília, Embrapa Hortaliças, 1989.

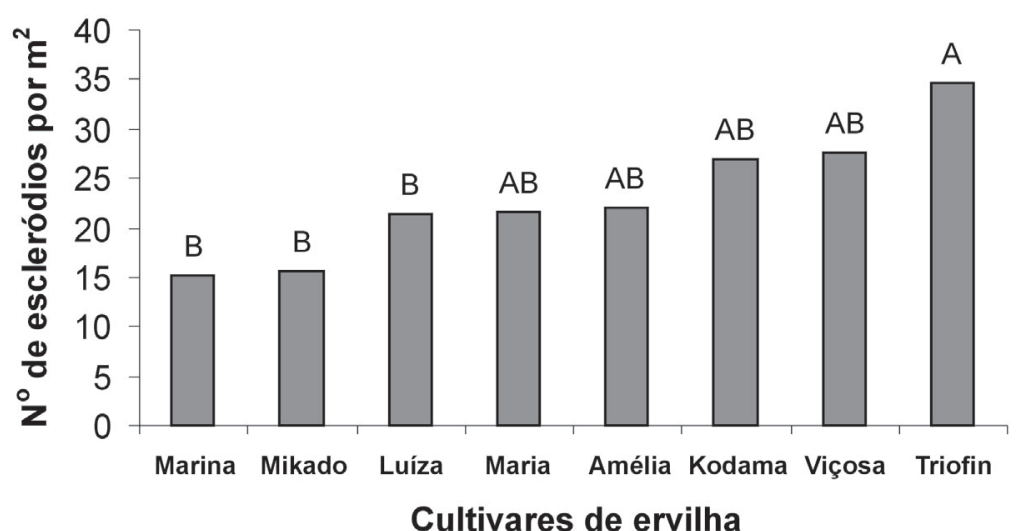

Figura 2. Número de escleródios para oito cultivares de ervilha. Brasília, Embrapa Hortaliças, 1989. (Médias seguidas da mesma letra não diferiram entre si a 5\% de probabilidade pelo teste Tukey).

ção dos grãos, que apresentou uma média de $1935 \mathrm{~g} /$ parcela ou seja, $2,42 \mathrm{t} / \mathrm{ha}$.

O peso seco da parte aérea das plantas, não variou estatisticamente entre cultivares, mas foi afetado pela lâmina total de água aplicada. A equação de regressão ajustada para explicar o efeito da lâmina de água (x), para todas as cultivares, sobre a produção de biomassa aérea (MS) por metro quadrado é dada pela expressão MS $=60,4586+0,8992 x$ - $0,00073 \mathrm{x}^{2}-4,1619 \mathrm{E}-07 \mathrm{x}^{3}$, com r ${ }^{2}=$ 0,99 (Figura 1). Através da equação ajustada o valor máximo de $278,7 \mathrm{~g} / \mathrm{m} 2$ é obtido para a lâmina de $444,7 \mathrm{~mm}$, observando-se o efeito negativo sobre esta característica a partir de lâminas de água maiores. Ao contrário do que se esperava a biomassa aérea final de cultivares com folhas normais e semi-áfilas foram similares, o padrão de senescência e deiscência dos diversos tipos de folhas talvez possa explicar este comportamento que necessita ser melhor quantificado. Para todas as cultivares houve redução no crescimento da parte aérea da planta quanto menor a lâmina total de água aplicada.

O número de escleródios foi significativamente afetado tanto pela lâmina total de água aplicada quanto pela cultivar (Figuras 1 e 2). Independentemente da cultivar utilizada, houve redução no número de escleródios (NE) por metro quadrado de área plantada com a redução da lâmina total de água aplicada e da biomassa aérea (Figura 1). A equação logística de regressão ajustada foi $\mathrm{NE}=-1,1938+69,0882 /[1+(\mathrm{x} /$ $360,4629) \wedge(-6,1378)]$, com r $\mathrm{r}^{2}=0,99$. Assim, ao irrigar demasiadamente uma cultura se está favorecendo a produção de escleródios que, juntamente com outros fatores, irão contribuir para a redução da biomassa final da planta conforme evidenciado pelas duas curvas da Figura 1.

Em relação às cultivares, o fato dos genótipos com folhagem semi-áfila, Amélia e Kodama não diferirem das demais, quanto a produção de escleródios, sugere que diferenças na arquitetura (número de folhas e gavinhas, principalmente) dessas cultivares não foram suficientes para reduzir a produção de escleródios, obtida sob as condições edafoclimáticas e densidade de plantio estudadas. A não existências de diferenças estatísticamente significativas na biomassa aérea de plantas semi-áfilas e com folhas normais ajuda a explicar este resultado.

As cultivares Triofin e Marina, Mikado e Luíza apresentaram, respectivamente, as maiores e menores produções de escleródios (Figura 2) em relação às demais cultivares indicando que existem diferenças genotípicas entre elas. Assumindo que a presença de propágulos se correlaciona positivamente com a resistência de campo a esclerotinia, os resultados sugerem que as cultivares Marina, Mikado e Luíza, por não diferirem estatisticamente entre si, podem apresentar maior resistência de campo à podridão-de-esclerotínia do que a cultivar Triofin. Assim, devese preferir as cultivares que reduzem o potencial de inóculo de esclerotinia em áreas sob irrigação por aspersão e em áreas onde não existam muitas opções de rotação de culturas. Entretanto, a prática do manejo integrado da água do solo e de cultivares mais resistentes deve ser estimulada, por razões óbvias.

Os resultados observados, 70 dias após o plantio e após a floração, para 
Tabela 1. Severidade de oídio em oito cultivares de ervilha submetidas a diferentes lâminas totais de água, 70 dias após o plantio. Brasília, Embrapa Hortaliças, 1989.

\begin{tabular}{ccccccccccc}
\hline Lâmina de & \multicolumn{10}{c}{ Cultivar } \\
\cline { 2 - 9 } água $(\mathbf{m m})$ & Maria & Triofin & Luíza & Viçosa & Marina & Kodama & Mikado & Amélia \\
\hline 303 & $1,0 \mathrm{a}^{*}$ & $1,0 \mathrm{~b}$ & $1,0 \mathrm{c}$ & $1,0 \mathrm{~d}$ & $1,0 \mathrm{e}$ & $1,0 \mathrm{f}$ & 1,4 & $\mathrm{de}$ & 2,0 & $\mathrm{~cd}$ \\
250 & $1,0 \mathrm{a}^{/ 1}$ & $1,0 \mathrm{~b}$ & $1,0 \mathrm{c}$ & $1,0 \mathrm{~d}$ & $1,0 \mathrm{e}$ & $1,0 \mathrm{f}$ & 1,4 & $\mathrm{de}$ & 2,0 & $\mathrm{~cd}$ \\
204 & $1,0 \mathrm{a}$ & $1,0 \mathrm{~b}$ & $1,0 \mathrm{c}$ & $1,0 \mathrm{~d}$ & $1,0 \mathrm{e}$ & $1,0 \mathrm{f}$ & 1,8 & $\mathrm{cde}$ & 2,5 & $\mathrm{bc}$ \\
162 & $1,0 \mathrm{a}$ & $1,0 \mathrm{~b}$ & $1,0 \mathrm{c}$ & $1,0 \mathrm{~d}$ & $1,0 \mathrm{e}$ & $1,1 \mathrm{f}$ & 2,0 & $\mathrm{~cd}$ & 2,9 & $\mathrm{~b}$ \\
125 & $1,0 \mathrm{a}$ & $1,0 \mathrm{~b}$ & $1,0 \mathrm{c}$ & $1,0 \mathrm{~d}$ & $1,1 \mathrm{e}$ & $1,5 \mathrm{f}$ & 2,5 & $\mathrm{bc}$ & 3,3 & $\mathrm{ab}$ \\
114 & $1,1 \mathrm{a}$ & $1,1 \mathrm{~b}$ & $1,1 \mathrm{c}$ & $1,0 \mathrm{~d}$ & $1,5 \mathrm{e}$ & $1,8 \mathrm{f}$ & $3,3 \mathrm{ab}$ & $4,0 \mathrm{a}$ \\
\hline
\end{tabular}

* Médias seguidas de mesma letra nas colunas não diferem entre si a 5\% de probabilidade pelo teste Tukey.

${ }^{/ 1}$ Severidade de oídio avaliada através de escala visual de notas, sendo 1 = ausência da doença; 2 = severidade baixa; $3=$ severidade média e 4 = severidade alta.

severidade de infecção de oídio proveniente de inoculações obtidas naturalmente sob condições de campo e cuja interação lâmina de água aplicada x cultivar foi significativa, mostraram as cultivares suscetíveis Amélia e Mikado com notas de severidade de oídio inversamente proporcionais à lâmina de água aplicada (Tabela 1). A cultivar Kodama apresentou uma tendência de quebra da susceptibilidade para menores lâminas de água aplicada. As demais cultivares não apresentaram este comportamento e confirmaram a sua resistência a esta doença (Giordano et al., 1988) independentemente do nível de irrigação.

O comportamento observado nas cultivares consideradas suscetíveis a oídio, por sua vez, evidencia que elevadas precipitações podem reduzir o potencial de inóculo, devido à maior remoção ou lavagem da fonte de inóculo das partes aéreas das plantas (Sivaplan, 1993). Considerando que o oídio é um parasita obrigatório, com nenhuma capacidade saprofítica, a simples remoção do esporo da planta para o solo reduz a fonte de inóculo secundário dentro da lavoura. Por outro lado, a maior incidência de oídio nos tratamentos menos irrigados, também pode ser explicada pelos frequientes relatos da literatura mostrando que diversas culturas, quando estão submetidas a menores lâminas de água e consequentemente nutrientes, podem reduzir ou acelerar o seu ciclo de vida e se tornarem mais suscetíveis ao ataque e desenvolvimento de doenças em geral.

Ao usar a irrigação por aspersão, como parte do manejo integrado dessas duas doenças, há que se levar em consideração que podridão-de-esclerotínia, representada pela produção de escleródios, e oidiose têm comportamentos opostos em relação à quantidade de água aplicada através da irrigação, ou seja, a produção de escleródios aumenta enquanto a severidade de oídio é reduzida sob maiores lâminas de água aplicada. Entretanto, considerando que a resistência genética existe somente para oídio, esforços devem ser feitos no sentido de maximizar a produção das cultivares resistentes ao oídio e, através do manejo adequado da irrigação e cultivares resistentes, minimizar a produção de escleródios e prováveis danos de esclerotínia. Portanto, as cultivares Maria e Marina, que são altamente resistentes a oídio, apresentam altas produtividades e praticamente tiveram o mesmo comportamento com relação a produção de escleródios (Figura 2), devem ter a preferência para plantio em locais naturalmente infestados por S. sclerotiorum.

\section{LITERATURA CITADA}

ANDREOLI, C. Avaliação do comportamento de algumas cultivares de ervilha (Pisum sativum L.) no Distrito Federal. Científica, Marília, v. 7, n. 3, p. 417-419, 1979.

BEHL, N.K.; SAWHNEY, J.S.; MOOLANI, M.K. Studies on water use in pea (Pisum sativum L.). Indian Journal of Agricultural Science, v. 38, n. 4, p. 623-633, 1968.

BOHN, G.W.; WHITAKER, T.W. Genetics of resistance to powdery mildew race 2 in muskmelon. Phytopathology, v. 54, n. 5, p. 587-590, 1964.

CAFÉ FILHO, A.C. Alerta aos produtores de ervilha - podridão-de-sclerotinia. Horticultura Brasileira, Brasília, v. 3, n. 2, p. 57, 1985.
CAFÉ FILHO, A.C.; MENEZES, L.W.; MADEIRA, M.C.B.; GIORDANO, L.B.; REIFSCHNEIDER, F.J.B. Avaliação de fungicidas para o controle químico do oídio da ervilha. Fitopatologia Brasileira, Brasília, v. 13, p. 369-372, 1988.

CHAUHAN, D.R.; PANWAR, K.S.; BALYAN, R.S. Influence of irrigation, phosphorus and weed-control methods on weeds and field pea (Pisum sativum L.). Tropical pest management. v. 38, n. 1, p. 1-4, 1992.

GIORDANO, L.B.; FRANÇA, F.H.; CRISÓSTOMO, L.A.; SILVA, C.B.; AGUILAR, J.A.E.; REIFSCHNEIDER, F.J.B.; ROCHA, F.E.C.; DIAS, J.A.A.; PAEZ, P.B.; Cultivo da ervilha (Pisum sativum L.). 2 ed. Brasília: EMBRAPA-CNPH, 1984. 12 p. (Instruções Técnicas 1)

GIORDANO, L.B.; REIFSCHNEIDER, F.J.B.; NASCIMENTO, W.M. Ervilha - Novas cultivares para produção de grãos secos. Brasília: EMBRAPA-CNPH, 1988. Folder

HADDOCK, J.L.; LINTON, D.C. Yield and phosphorus contents of canning peas as affected by fertilization, irrigation regime and sodium bicarbonate-soluble soil phosphorus. Soil Science of America Proceedings, v. 21, n. 2, p. 167-171, 1957.

HANKS, R.J.; SISSON, D.V.; HURST, R.L.; HUBBARD, K.G. Statistical analysis of results from irrigation experiments using the linesource sprinkler system. Soil Science Society of America Journal, v. 44, p. 886-888, 1980.

HAWTHORN, L.R.; POLLARD, L.H. Effect of soil moisture, soil fertility, and rate of seeding on the yield, viability, and quality of seed peas. Bulletin of Utah Agricultural Experiment Station., 1966. 19 p.

MAROUELLI, W.A; GIORDANO, L.B.; OLIVEIRA, C.A.S.; CARRIJO, O.A. Desenvolvimento, produção, e qualidade de ervilhas sob diferentes tensões de água no solo. Pesquisa Agropecuária Brasileira, Brasília, v. 26, n. 7, p. 1041-1047, 1991.

MILLER, D.G.; MANNING, C.E.; TEARE, I.D. Effects of soil water levels on components of growth and yield in peas. Journal of the American Society for Horticultural Science, v. 102, n. 3, p. 349-351, 1977.

OLIVEIRA, H.A. Produção de sementes de ervilha no Brasil. Pelotas: IPEAS, 1965.16 p. (Circular 25). 
SALTER, P.J. Some response of peas to irrigation at different growth stages. Journal of Horticultural Science, v. 37, p. 141-149, 1962.

SALTER, P.J. The effect of wet or dry soil conditions at different growth stages on the components of yield of a pea crop. Journal of Horticultural Science, v. 38, p. 321-334, 1963.

SALTER, P.J.; WILLIAMS, J.B. The effect of irrigation on pea crops grown at different plant densities. Journal of Horticultural Science, v. 42, p. 59-66, 1967.

SANTOS, J.R.M. Efeito de cultivares e densidades de plantio na produção de escleródios de Sclerotinia sclerotiorum em ervilha. Fitopatologia Brasileira, Brasília, v. 15, n. 2, p. 135, 1990. Resumo.
SANTOS, J.R.M.; CHARCHAR, J.M.; NASSER, L.C.B. Levantamento de patógenos que afetam ervilha irrigada no Distrito Federal. Fitopatologia Brasileira, Brasília, v. 5, n. 1, p. 98-99, 1990.

SANTOS, J.R.M.; PESSOA, H.B.S.V.; GIORDANO, L.B. Resistência de campo a oídio (Oidium sp.) em germoplasma de ervilha (Pisum sativum). Fitopatologia Brasileira, Brasília, v. 18, n. 1, p. 123-125, 1993.

SANTOS, J.R.M.; REIFSCHNEIDER, F.J.B Doenças e patógenos descritos em ervilha. Fitopatologia Brasileira, Brasília, v. 15, n. 3, p. 238-243, 1990.
SCHNATHORST, W.C. Environmental relationships in the powdery mildews. Annual Review of Phytopathology, v. 3, p. 343-366, 1965.

SCHWARTZ, H.F.; GÁVEZ, G.E. Problemas de producción del fríjol: enfermidades, insectos, limitações edáficas y climáticas de Phaseolus vulgaris. Cali: CIAT, 1980. p. 127-151.

SIVAPLAN, A. Effects of impacting rain drops on the growth and development of powdery mildew fungi. Plant Pathology, v. 42, n. 2, p. 256-263, 1993.

YARWOOD, C.E. Powdery mildews. The Botanical Review, v. 23, p. 235-293, 1957. 